\title{
The impact of parents' expectations on parenting behaviour: an experimental investigation
}

Article

Published Version

Creswell, C., O'Connor, T. G. and Brewin, C. R. (2008) The impact of parents' expectations on parenting behaviour: an experimental investigation. Behavioural and Cognitive Psychotherapy, 36 (4). pp. 483-490. ISSN 1352-4658 doi: https://doi.org/10.1017/s1352465808004414 Available at https://centaur.reading.ac.uk/14098/

It is advisable to refer to the publisher's version if you intend to cite from the work. See Guidance on citing.

To link to this article DOI: http://dx.doi.org/10.1017/s1352465808004414

Publisher: Cambridge University Press

All outputs in CentAUR are protected by Intellectual Property Rights law, including copyright law. Copyright and IPR is retained by the creators or other copyright holders. Terms and conditions for use of this material are defined in the End User Agreement.

www.reading.ac.uk/centaur 
Central Archive at the University of Reading

Reading's research outputs online 


\title{
The Impact of Parents' Expectations on Parenting Behaviour: An Experimental Investigation
}

\author{
Cathy Creswell \\ University of Reading, UK \\ Thomas G. O’Connor \\ University of Rochester Medical Center, USA
}

Chris R. Brewin

University College London, UK

\begin{abstract}
Over-involved parenting is commonly hypothesized to be a risk factor for the development of anxiety disorders in childhood. This parenting style may result from parental attempts to prevent child distress based on expectations that the child will be unable to cope in a challenging situation. Naturalistic studies are limited in their ability to disentangle the overlapping contribution of child and parent factors in driving parental behaviours. To overcome this difficulty, an experimental study was conducted in which parental expectations of child distress were manipulated and the effects on parent behaviour and child mood were assessed. Fifty-two children (aged $7-11$ years) and their primary caregiver participated. Parents were allocated to either a "positive" or a "negative" expectation group. Observations were made of the children and their parents interacting whilst completing a difficult anagram task. Parents given negative expectations of their child's response displayed higher levels of involvement. No differences were found on indices of child mood and behaviour and possible explanations for this are considered. The findings are consistent with suggestions that increased parental involvement may be a "natural" reaction to enhanced perceptions of child vulnerability and an attempt to avoid child distress.
\end{abstract}

Keywords: Parents, cognitions, expectations, behaviour, over-involvement.

\section{Introduction}

Parental over-involvement or lack of autonomy granting is associated with child anxiety and anxious symptoms (e.g. McLeod, Wood and Weisz, 2007; Rapee, 1997; Wood, McLeod, Sigman, Hwang and Chu, 2003). Developmental theories of childhood anxiety

Reprint requests to Cathy Creswell, School of Psychology, University of Reading, Whiteknights, Reading, Berkshire RG66AL, UK. E-mail: c.creswell@reading.ac.uk 
(e.g. Chorpita and Barlow, 1998; Hudson and Rapee, 2004; Rapee, 2001) suggest that overinvolved parenting behaviour (i.e. parental intrusiveness in contrast to encouragement of autonomy and independence), in the context of a predisposition to anxiety, increases the likelihood of the development of a childhood anxiety disorder. Specifically, this behaviour is hypothesized to enhance/reinforce children's anxious cognitions (i.e. the child's tendency to perceive events as threatening and her/himself as lacking in control or effectiveness), and behaviours (i.e. their tendency to avoid potentially threatening situations). Moreover, recent treatment studies (Wood, Piacentini, Southam-Gerow, Chu and Sigman, 2006) suggest that altering parental behaviour may be an important aim of intervention for childhood anxiety and may mediate treatment outcomes. The current study contributes to this line of investigation by investigating sources of parental over-involved behaviour using an experimental manipulation, a design that has been rarely used in this line of research, and observing parental behaviour following an experimental manipulation.

Competing explanations have been proposed for parental over-involved behaviour. Perhaps the most common account in the literature is that over-involved parental behaviour reflects parents' attempts to prevent their child's distress based on parental expectations - which may or may not be accurate - that the child will not cope effectively. For example, Barrett, Rapee, Dadds and Ryan (1996) found that parents of anxious children accurately predicted that their children would interpret ambiguous scenarios as threatening and choose an avoidant solution. Comparable findings were reported by Kortlander, Kendall and Panichelli-Mindel (1997).

Although there is substantial support for the parental expectation model, including recent longitudinal findings (Creswell, O'Connor and Brewin, 2006), the evidence is based on naturalistic studies that are unable to de-confound the contributions of child behaviour and parent behaviour, and the overlap between the two. That is a potentially significant limitation because parent and child contributors to parental expectations and behaviour would overlap considerably for genetic and psychosocial reasons. Furthermore, few studies have included observations of parental behaviour, and so are unable to directly link expectations and parental over-involvement.

The current study was designed to build on existing research on parental expectations in three ways. First, by including an experimental manipulation of parental expectations that would offer particular leverage for testing hypotheses about the source of parental over-involvement. Second, by including direct measures of parental over-involved behaviour, as a direct test of the link between parental expectation and parental behaviour. Third, by assessing the effects of parental expectations and over-involved behaviour on the child. Two hypotheses were tested: (i) Parents who expected their child to be more distressed (following experimental manipulation) would be more involved in their behaviour towards their child; (ii) Children would show more distress/anxiety in response to elevated parental expectations of child distress and parental over-involved behaviour.

\section{Method}

\section{Participants}

The sample comprised 52 children and their primary caregiver. Children were all aged between 7 and 11 years of age (mean age $=9.06, S D=1.06$ ) and were recruited through letters sent to parents and children via local primary schools, after obtaining permission from school 
head-teachers. The inclusion criteria for the study required that both parent and child were fluent English speakers for practical purposes. Families were randomly allocated to two groups of 26 child-parent dyads, subject to the constraint that the eventual groups did not differ according to child age (means group 1: 9.04 years; group 2: 9.08 years), child gender (group 1: 14 male; group 2: 16 male), parent gender (group 1: 1 father; group 2: 2 fathers), and parent and child trait anxiety scores (see below) (Parent anxiety means, group 1: 40.81; group 2: 37.58) (Child anxiety means, group 1: 33.46; group 2: 35.92). The sample size was based on a power analysis to obtain sufficient power to detect differences in parent behaviour with an effect size of at least 0.8 (from Hudson and Rapee, 2001).

\section{Procedure}

Prior to attending the appointment, parents returned the Trait scales of the State Trait Anxiety Inventory- Trait (Spielberger, 1983) and State Trait Anxiety Inventory for ChildrenParent report (Spielberger, 1973) for matching purposes. These scales both measure enduring tendencies to experience anxiety and both are known to have good psychometric properties (Spielberger, 1973, 1983). On arrival at the laboratory, parents and children were given brief instructions regarding the procedure of the study before being taken to separate rooms where they completed anxiety measures for a second time; these data were used to confirm accurate matching of group participants. The parent-child interaction was based around a difficult anagram task (following Woodruff-Borden, Morrow, Bourland and Cambron, 2002). Parents were given the following instructions: "Your child will now be given a set of word puzzles to do. The puzzles are anagrams. This means we will give your child sets of letters that make a word, but the letters are in the wrong order. Your child's task is to work out what the word should be and to put the letters in the right order in the box provided. Your child will be given 10 minutes to get as many right as s/he can. You will be with your child whilst s/he does this task. First we would like you to explain the task to your child so s/he knows what to do. During the task you are free to help your child in whatever way you think is appropriate, but we would ask you not to give your child the actual answer if you work it out first. We would like your child to actually solve the problem him/herself." Group 1 (positive expectations) were also given the following instructions: "The puzzles we are giving your child are tricky but we expect s/he will find them fun to do and enjoy the challenge." Group 2 (negative expectations) were given the following instructions: "The puzzles we are giving your child are tricky. We expect s/he might struggle with the task, which may become upsetting for him/her at some point during the task." As a manipulation check, after receiving the full instructions parents were asked to rate on three 11-point scales (from 0 to 10$)$, how difficult $(0=$ very easy, $10=$ very difficult), worried and upset $(0=$ not at all, $10=$ very $)$ they expected their child to be during the task.

Parents then joined their child and the experimenter gave the family the anagram task facedown, to turn over as the experimenter left the room. The list of 15 anagrams were real words that had been administered to 10 children aged 11 years of age. The first two words given were solved by all children in the pilot ("banana" and "monkey"), but none of the pilot children had been able to generate solutions to the remainder during a 10-minute period (e.g. "sabbatical", "fabricate"). The interaction between the parent and child was then videorecorded whilst they were left to attempt the task for 10-minutes. At the end of the 10-minute period, the parent and child were again taken to separate rooms. Children were asked to rate 
on three 11-point scales how difficult they found the task and how worried and upset they were by it.

On completion of the study the parent and child were debriefed about the purpose of the study and the experimental manipulation was highlighted. Children were given a set of easy age-appropriate anagrams with pictorial clues to complete prior to leaving. Participating families each received a $£ 10.00$ gift voucher in appreciation of their time and co-operation.

\section{Coding of parent-child interactions}

Each 10-minute parent-child interaction was rated on five global scales following the coding scheme of Hudson and Rapee (2001). Each scale comprised a 9-point (0-8) continuum, where 0 represented "very uninvolved" and 8 represented "very overinvolved". The scales measured parental involvement, specifically: (i) general involvement (degree to which the parent allowed the child to complete the task independently); (ii) unsolicited help (degree to which the parent gives help when it is not needed); (iii) touching of anagram puzzle or pencil; (iv) parent's focus (degree to which the parent is "task" versus "child" focused); (v) parent's posture (degree to which the parent leans in over the child versus sits back). An additional scale was added to assess the child's negative affect during the task, in which 0 represented very positive affect (happy and relaxed, no evidence of tension) and 8 represented negative affect (frustration, sadness, aggression). The coded observation of child affect covered a broad spectrum of negative responses because of our interest in identifying a broad array of negative responses that may be linked with anxiety in young children (ADIS-IV; Silverman and Albano, 1996).

Three independent coders (two psychology Masters students and one psychology graduate, blind to experimental group) rated all videos. All raters were trained in the coding of the interaction clips over a 16-hour period by the end of which coders reached consensus on $90 \%$ of ratings. Subsequent to the training period, coders rated the video clips independently, but came together to rate every fifth clip as a group and to reach consensus to prevent rater drift. Intraclass correlations for each of the parental behaviour scales and the child affect scale was good (ICC $=.75-.88$ ) with the exception of parent focus (ICC $=.53,95 \% \mathrm{CI}=.20-.74)$. This scale was therefore excluded from further analyses.

\section{Results}

Variables were screened following Tabachnick and Fidell (1996) and data met the assumptions required for parametric tests with the exception of the variable parents' expectations of child upset (1) which significantly differed from normality in the extent of kurtosis. Standard transformations did not improve the fit of the distribution, so non-parametric tests were applied when considering this variable. In accordance with the unidirectional hypotheses, one-tailed tests of significance were applied.

Means and standard deviations for parents' expectations are given in Table 1. Parents in the two experimental groups differed in their expectations of how their child would find the task in the anticipated direction. Parents given negative task instructions expected their child to find the task more difficult, be more worried and more upset during the task when compared to parents given positive task instructions.

Consistent with hypothesis 1 , parents given negative expectations of how their child would find the task were rated as (i) significantly more involved generally $(t(50)=1.76, p=.04)$ 
Table 1. Means and standard deviations on parent and child ratings

\begin{tabular}{|c|c|c|c|c|c|}
\hline & \multicolumn{2}{|c|}{$\begin{array}{c}\text { Group } 1 \\
\text { (positive expectations) } \\
n=26\end{array}$} & \multicolumn{2}{|c|}{$\begin{array}{c}\text { Group } 2 \\
\text { (negative expectations) } \\
n=26\end{array}$} & \multirow[b]{2}{*}{$\mathrm{t}(50)$} \\
\hline & mean $(S D)$ & range & mean $(S D)$ & range & \\
\hline \multicolumn{6}{|c|}{ Parent expectations' prior to task: } \\
\hline Difficult & $4.16(2.51)$ & $0-9$ & $5.48(1.96)$ & $2-10$ & $2.07^{*}$ \\
\hline Worried & $3.20(2.69)$ & $0-9$ & $5.24(2.54)$ & $0-10$ & $2.76^{* *}$ \\
\hline Upset & $2.20(2.33)$ & $0-7$ & $4.60(2.55)$ & $0-8$ & $154^{* *^{1}}$ \\
\hline \multicolumn{6}{|l|}{ Post task: } \\
\hline Difficult & $8.46(1.56)$ & $3-10$ & $9.04(.96)$ & $7-10$ & 1.61 \\
\hline Worried & $4.92(2.95)$ & $0-10$ & $5.08(2.28)$ & $1-9$ & .21 \\
\hline Upset & $3.62(2.90)$ & $0-10$ & $3.54(2.35)$ & $0-8$ & .11 \\
\hline \multicolumn{6}{|l|}{ Child self-report post task: } \\
\hline Difficult & $8.35(1.92)$ & $3-10$ & $7.65(1.70)$ & $2-10$ & 1.38 \\
\hline Worried & $3.58(3.06)$ & $0-10$ & $3.00(2.86)$ & $0-9$ & .70 \\
\hline Upset & $1.46(2.50)$ & $0-10$ & $1.23(1.99)$ & $0-7$ & .37 \\
\hline \multicolumn{6}{|l|}{ Observations: } \\
\hline Child negative affect & $3.73(1.00)$ & $2-6$ & $3.26(1.03)$ & $1-6$ & 1.56 \\
\hline \multicolumn{6}{|l|}{ Parent behaviour during task: } \\
\hline General involvement & $3.69(1.30)$ & $1-6$ & $4.19(1.15)$ & $2-7$ & $1.76^{*}$ \\
\hline Unsolicited help & $3.33(1.32)$ & $1-6$ & $3.80(1.20)$ & $1-7$ & 1.36 \\
\hline Parent touching of puzzle & $3.81(1.00)$ & $2-6$ & $4.25(.97)$ & $0-7$ & 1.59 \\
\hline Parent posture & $4.91 \quad(.78)$ & $3-7$ & $5.31 \quad(.95)$ & $2-7$ & $1.67^{*}$ \\
\hline
\end{tabular}

$p<.05 ;{ }^{* *} p<.01 ;{ }^{* * *} p<.001 ;{ }^{1}$ Mann-Whitney U.

and (ii) displaying more involved posture $(t(50)=1,67, p=.05)$ than parents given positive expectations. Unsolicited help $(t(50)=1.36, p=.09)$ and parental touching of the puzzle or pencil were not significantly different across groups $(\mathrm{t}(50)=.87, \mathrm{p}=.17)$.

However, in contrast to hypothesis 2 , children's self-reported difficulty, worry and distress immediately after the task and observed negative emotions did not differ according to experimental group. Parents also did not differ in their reports of their child's difficulty, worry and upset immediately after the task (Table 1).

\section{Discussion}

The current study used a novel experimental manipulation of parental expectations of child coping to investigate the impact of parental expectations on parenting behaviours. The effect on child response to the parental expectations and behaviour was also examined. Manipulation checks confirmed that parents who were given the negative manipulation expected their child to become more upset, to find the task more difficult, and to be more worried by it. In support of our hypotheses, parents who were given negative expectations for their child displayed more involvement during the challenging task, specifically in terms of general involvement and non-verbal behaviour. Group differences were not, however, found on child reported difficulty, worry and distress, or observations of affect. The findings add strength to the model 
in which parental expectations lead to more involved parental behaviour, a process that has been largely confined to naturalistic or observational studies that have not been able to test the specific, independent role of parental expectations on parental behaviour.

It was somewhat surprising that the parental manipulation did not have the expected carryover effects to the child, at least in terms of the affect codes assessed in this report. This indicates that among non-clinical families and in the context of an objectively difficult task, the parental response of increased involvement may not necessarily influence child behaviour in a direct and immediate way. Whether or not this carries over to families with clinically elevated anxiety is not clear from this study, but has been suggested (e.g. Chorpita and Barlow, 1998; Hudson and Rapee, 2004). It remains to be seen if findings derived from studies that capitalize on the advantages of experimental manipulations in clinic samples are similar to what has been shown in studies using non-clinical samples and non-experimental methods.

The lack of group differences with regard to child self-reported response may be explained by a number of factors. First, whilst group differences were found for parenting behaviour, the actual differences were small and the mean scores for involvement fell close to the midpoint score for both groups (representing behaviour considered to be neither over-involved nor uninvolved). These differences may have been insufficient to elicit differences in child response. That may reflect the non-clinical nature of the sample; stronger effects might be expected in clinic-referred parents and children (but for whom experimental manipulations of this sort might be seen as ethically questionable). Measures of child response may also have been insensitive to group differences. On rating scales, children generally rated a very high level of difficulty for the task and a low level of distress caused by it. A number of children subsequently reported that they were not upset by it because it was "just an experiment"; "It wasn't like a test at school or anything".

Additional limitations should also be noted. The age range of participating children was restricted, to 7-11 years, in the current study as parents' expectations (Dix, Ruble, Grusec and Nixon, 1986) and behaviour (e.g. Hudson and Rapee, 2001) alter with child age. Use of larger sample sizes and broader age ranges would be useful extensions to this study. Similarly, the sample size did not allow for adequate consideration of interactive effects of parents' expectations with child gender, which might be expected based on findings that parents behave differently with their shy girls and boys (Stevenson-Hinde and Glover, 1996). The current study included a small number of fathers, which meant that it was not possible to assess interactive effects of parent gender and expectations on parent behaviour. Finally, the current sample comprises a non-clinical population where parent self-reported anxiety was matched across groups. The study was not able, therefore, to assess the interactive effects of parental anxiety with parents' expectations (e.g. Cobham, Dadds and Spence, 1999; Wheatcroft and Creswell, 2007).

With the above limitations in mind, the current study has the strength of invoking an experimental manipulation to provide a clear test of the effects of parents' cognitions on their behaviours in interaction with their child. The study provides support for the hypothesis that parents' expectations of child distress lead to increased parental involvement when a child is confronted with a challenging task. This is consistent with theories of the development of anxiety in childhood that suggest that parental over-involvement may be a "natural" reaction to enhanced perceptions of child vulnerability and an attempt to avoid child distress (e.g. Hudson and Rapee, 2004; Rapee, 2001) (which may indeed be successful amongst nonclinical children). As such, these findings are consistent with the development of models 
of parental responses to their children that incorporate both parental cognitions as well as behaviours, and specifically parental expectations about their child's capabilities.

\section{Acknowledgments}

The authors are grateful to Vicki Preston-Ladd, Klea Imamidou and Anna Barnes for their help with coding observational data. We are also of course extremely grateful to all the families who took part in this research.

\section{References}

Barrett, P. M., Rapee, R. M., Dadds, M. M. and Ryan, S. M. (1996). Family enhancement of cognitive style in anxious and aggressive children. Journal of Abnormal Child Psychology, 24, 187203.

Chorpita, B. F. and Barlow, D. H. (1998). The development of anxiety: the role of control in the early environment. Psychological Bulletin, 124, 3-21.

Cobham, V. E., Dadds, M. M. and Spence, S. H. (1999). Anxious children and their parents: what do they expect? Journal of Clinical Child Psychology, 28, 220-231.

Creswell, C., O'Connor, T. and Brewin, C. (2006). A longitudinal investigation of maternal and child "anxious cognitions". Cognitive Therapy and Research, 30, 135-147.

Dix, T., Ruble, D. N., Grusec, J. E. and Nixon, S. (1986). Social cognition in parents: inferential and affective reactions to children of three age levels. Child Development, 57, 879-894.

Hudson, J. L. and Rapee, R. M. (2004). From anxious temperament to disorder: an etiological model of Generalized Anxiety Disorder. In R. G. Heimberg, C. L. Turk and D. S. Mennin (Eds.), Generalized Anxiety Disorder: advances in research and practice (pp. 51-74). New York: Guilford Press.

Hudson, J. and Rapee, R. M. (2001). Parent-child interactions and anxiety disorders: an observational study. Behaviour, Research and Therapy, 39, 1411-1427.

Kortlander, E., Kendall, P. C. and Panichelli-Mindel, S. M. (1997). Maternal expectations and attributions about coping in anxious children. Journal of Anxiety Disorders, 11, 297-315.

McLeod, B. D., Wood, J. J. and Weisz, J. R. (2007). Examining the association between parenting and child anxiety: a meta-analysis. Clinical Psychology Review, 27, 155-172.

Rapee, R. M. (1997). Potential role of childrearing practices in the development of anxiety and depression. Clinical Psychology Review, 17, 47-67.

Rapee, R. M. (2001). The development of generalized anxiety. In M. W. Vasey and M. M. Dadds (Eds.), The Developmental Psychopathology of Anxiety (pp. 1045-1095). New York: Oxford University Press.

Silverman, W. K. and Albano, A. M. (1996). Anxiety Disorders Interview Schedule for DSM-IV: child and parent versions. San Antonio: The Psychological Corporation.

Spielberger, C. D. (1973). Manual for State-Trait Anxiety Interview for Children. Palo Alto, CA: Consulting Psychologists Press.

Spielberger, C. D. (1983). State-Trait Anxiety Inventory Manual. Palo Alto, CA: Mind Garden.

Stevenson-Hinde, J. and Glover, A. (1996). Shy girls and boys: a new look. Journal of Child Psychology and Psychiatry, 37, 181-187.

Tabachnick, B. G. and Fidell, L. S. (1996). Using Multivariate Statistics. (3rd ed.). New York: Harper Collins College Publishers.

Wheatcroft, R. and Creswell, C. (2007). Parental cognitions and expectations of their preschool children: the contribution of parental anxiety and child anxiety. British Journal of Developmental Psychology, 25, 435-441. 
Wood, J. J., Piacentini, J. C., Southam-Gerow, M., Chu, B. C. and Sigman, M. (2006). Family cognitive behavioral therapy for child anxiety disorders. Journal of the American Academy of Child and Adolescent Psychiatry, 45, 314-321.

Wood, J. J., McLeod, B. D., Sigman, M., Hwang, W. and Chu, B. C. (2003). Parenting and childhood anxiety: theory, empirical findings, and future directions. Journal of Child Psychology and Psychiatry, 44, 134-151.

Woodruff-Borden, J., Morrow, C., Bourland, S. and Cambron, S. (2002). The behavior of anxious parents: examining mechanisms of transmission of anxiety from parent to child. Journal of Clinical Child and Adolescent Psychology, 31, 364-374. 